\title{
Fault-Tolerant Control of a Wind Turbine Generator Based on Fuzzy Logic and Using Ensemble Learning
}

\author{
Jordi Cusidó $^{1,2, *(\mathbb{D})}$, Arnau López ${ }^{2}$ and Mattia Beretta ${ }^{1,2}$ (D) \\ 1 SMARTIVE, Ps. Almogàvers 44, 08204 Sabadell, Spain; mattia.beretta@smartive.eu \\ 2 Unitat Transversal de Gestió de l'Àmbit de Camins (UTGAC), Universitat Politécnica de Catalunya (UPC), \\ 08034 Barcelona, Spain; arnau.lopez.flores@estudiantat.upc.edu \\ * Correspondence: jordi.cusido@smartive.eu
}

Citation: Cusidó, J.; López, A.;

Beretta, M. Fault-Tolerant Control of a Wind Turbine Generator Based on Fuzzy Logic and Using Ensemble Learning. Energies 2021, 14, 5167. https://doi.org/10.3390/en14165167

Academic Editor: Surender

Reddy Salkuti

Received: 28 July 2021

Accepted: 19 August 2021

Published: 20 August 2021

Publisher's Note: MDPI stays neutral with regard to jurisdictional claims in published maps and institutional affiliations.

Copyright: (C) 2021 by the authors. Licensee MDPI, Basel, Switzerland. This article is an open access article distributed under the terms and conditions of the Creative Commons Attribution (CC BY) license (https:/ / creativecommons.org/licenses/by/ $4.0 /)$.

\begin{abstract}
Wind energy is a form of renewable energy with the highest installed capacity. However, it is necessary to reduce the operation and maintenance costs and extend the lifetime of wind turbines to make wind energy more competitive. This paper presents a power-derating-based FaultTolerant Control (FTC) model in $2 \mathrm{MW}$ three-bladed wind turbines implemented using the National Renewable Energy Laboratory's (NREL) Fatigue, Aerodynamics, Structures, and Turbulence (FAST) wind turbine simulator. This control strategy is potentially supported by the health status of the gearbox, which was predicted by means of algorithms and quantified in an indicator denominated as a merge developed by SMARTIVE, a pioneering of in this idea. Fuzzy logic was employed in order to decide whether to down-regulate the output power or not, and to which level to adjust to the needs of the turbines. Simulation results demonstrated that a reduction in the power output resulted in a safer operation, since the stresses withstood by the blades and tower significantly decreased. Moreover, the results supported empirically that a diminution in the generator torque and speed was acheived, resulting in a drop in the gearbox bearing and oil temperatures. By implementing this power-derating FTC, the downtime due to failure stops could be controlled, and thus the power production noticeably grew. It has been estimated that more than 325,000 tons of $\mathrm{CO}_{2}$ could be avoided yearly if implemented globally.
\end{abstract}

Keywords: FAST; wind turbine; fault-tolerant control; power derating; fuzzy logic

\section{Introduction}

The last decade has been characterized by a substantial shift toward renewable energy production, which in 2020 was 27\% (7.44 TWh) [1] of the global power generation capacity.

Wind energy is one of the most sustainable and important sources of energy, accounting for $21 \%(1.592 \mathrm{GWh})$ of total renewable electricity, and 5.9\% of the total energy pool (Figure 1). Due to technological advances made in the last decade, wind power has become more competitive with traditional power, the prices of which are experiencing exponential growth (Figure 2). However, wind energy needs to solve several challenges that do not allow it to be equally or more competitive with respect to traditional energy sources or renewable energies like hydropower and solar photovoltaic (PV), which has been the most installed renewable energy in the last three years. The main challenges are outlined below.

Cost reduction in operation and maintenance is required to make wind energy more competitive: On average, 3\% of the production time for turbines is downtime due to breakdowns and maintenance issues. In some parks, these figures are even higher, at $10-15 \%$, and can be at $30 \%$ in extreme cases (especially for the oldest ones). The global average downtime is $1-7$ days $[2,3]$.

Breakdown and maintenance incidents lead to production losses in the sector of over EUR 15 billion worldwide annually. On average, $60 \%$ of wind turbine downtime is unplanned; this of course includes many early turbines that are approaching the end of their life [4]. 


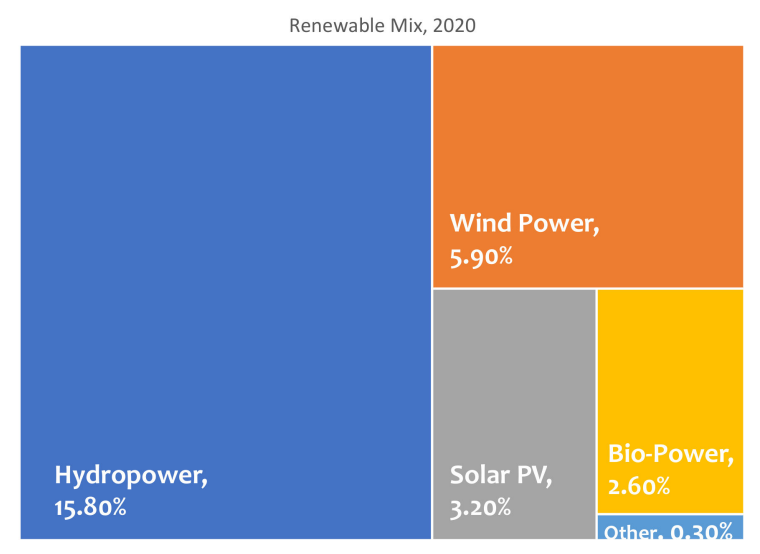

Figure 1. Renewable mix production in 2020 [1].

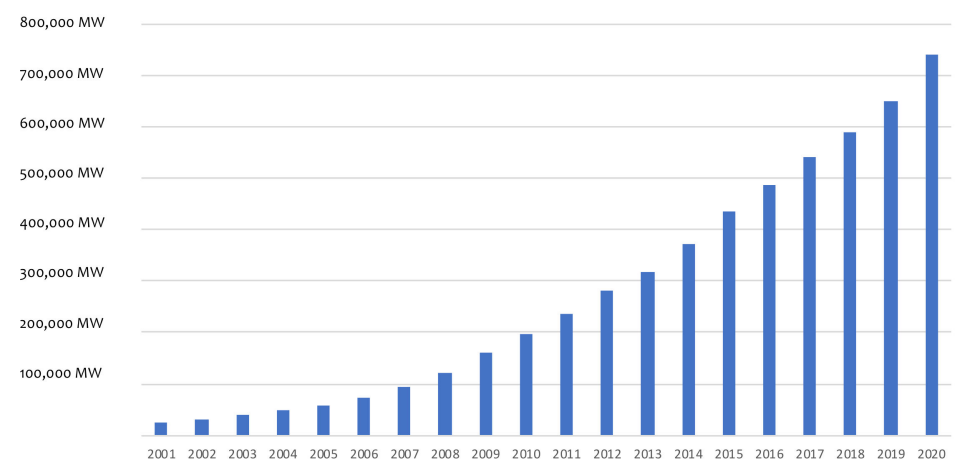

Figure 2. Annual growth of power renewable capacity source statista [5].

A common system fault involved the drive train, where the friction coefficient changes slowly with time. This problem brings with it two other fault patterns: problems with the rotor speed and generator speed measurements.

The problem with gearbox faults is that they are much slower than the system dynamics and the system sample rate, which makes them very hard to detect and isolate, and they therefore can trigger unexpected wind turbine (WT) stops. Table 1 shows different fault scenarios for WTs with their most common originating causes, and the percentage of these typical faults [6].

This work deals with faults in WT gearboxes. As studied in [7], any faults in the gearbox lead to a power output reduction. These faults can originate not only in the bearings of the gearbox, where most of failures currently occur, but also through uncontrolled vibrations and high oil temperatures, which are potential indicators of the presence of critical faults [8].

Fault-Tolerant Control (FTC), combined with early fault-detection techniques, provides a unique opportunity for continuous operation of wind turbines, allowing the operators to minimize production downtimes. In FTC, we must distinguish two main approaches: Passive FTC (PFTC) and Active FTC (AFTC) [9,10]. In Passive FTC design, the controller is optimized for the healthy operation mode, and some degraded performance is introduced when diagnosed faults occur. Active FTC can be solved using the Virtual Sensor and Actuator (VSA) approach or the Controller Reconfiguration (CR) scheme. Therefore, before applying any FTC solution, Fault Detection and Isolation (FDI) is needed. 
Table 1. Common faults in wind turbines [6].

\begin{tabular}{|c|c|}
\hline Types of Faults & Causes of Faults \\
\hline Faults in Blades and Rotors & $\begin{array}{l}\text { Corrosion of blades and hub; crack; reduced } \\
\text { stiffness; increased surface roughness; } \\
\text { deformation of the blades; errors of pitch angle; } \\
\text { and imbalance of rotors, etc. }\end{array}$ \\
\hline Faults in Gearbox & $\begin{array}{c}\text { Imbalance and misalignment of shaft; damage } \\
\text { of shaft, bearing and gear; broken shaft; high } \\
\text { oil temperature; leaking oil; and poor } \\
\text { lubrication, etc. }\end{array}$ \\
\hline Faults in Generator & $\begin{array}{l}\text { Excessive vibrations of generator; overheating } \\
\text { of generator and bearing; abnormal noises; and } \\
\text { insulation damage, etc. }\end{array}$ \\
\hline Faults in Bearing & $\begin{array}{l}\text { Overheating; and premature wear caused by } \\
\text { unpredictable stress, etc }\end{array}$ \\
\hline Faults in Main Shaft & $\begin{array}{l}\text { Misalignment; crack; corrosion; and coupling } \\
\text { failure, etc. }\end{array}$ \\
\hline Hydraulic Faults & Sliding valve blockage; oil leakage, etc \\
\hline Faults on Mechanical Breaking System & $\begin{array}{l}\text { Hydraulic failures; and wind speed exceeding } \\
\text { the limit, etc. }\end{array}$ \\
\hline Faults in Tower & $\begin{array}{l}\text { Poor quality control during the manufacturing } \\
\text { process, improper installation and loading; } \\
\text { harsh environment, etc. }\end{array}$ \\
\hline Faults on Electrical Systems/Devices & $\begin{array}{l}\text { Broken buried metal lines; corrosion or crack of } \\
\text { traces; board delamination; component } \\
\text { misalignment; electrical leaks; and cold-solder } \\
\text { joints, etc. }\end{array}$ \\
\hline Faults in Sensors & $\begin{array}{l}\text { Malfunction or physical failure of a sensor; } \\
\text { malfunction of hardware or the } \\
\text { communication link; and error of data } \\
\text { processing or communication software, etc. }\end{array}$ \\
\hline
\end{tabular}

In the literature, different approaches have been proposed for health analysis and failure detection. Pozo and Vidal proposed Principal Component Analysis (PCA) to compare the baseline and data coming from a wind turbine, and statistical hypothesis testing was used to determine failure conditions [11]. The drawback of this approach was that it requires high-frequency data, which is uncommon in SCADA systems. In the line of hypothesis testing, Hosseinzadeh et al. proposed the use of Maximum Power Point (MPP) analysis to determine failures of lubricant the authors introduced that the difference between the actual and estimated output power may indicate failure [12]. For a non-MPP, the authors proposed the use of the angular shaft speed ratio to determine failure. Nevertheless, the use of this information may work in simulations, but it is not usually reported by the standard Supervisory Control And Data Acquisition system (SCADA). Failure detection using SCADA data analysis was introduced in previous works. Zaher et al. proposed the use of anomaly detection for fault turbine identification [13]. More recent research proposed the use of Self-Organizing Maps (SOM) to determine turbine faults [14]. For the purpose of this research, the authors used an adaptation of ensemble learning recently published [15]. The advantage of using fault indicators is that the proposed solution might be applied to any wind turbine.

Initial FTC approaches in the literature analysed options using if-else rules focusing on torque and pitch controls loops [16]. In [17], Vidal et al. introduced Active FTC for pitch actuators, and Badihin presented FTC based on torque control [18]. Passive pitch FTC was presented at [10]. In [19], the authors proposed a set value-based observer method, 
and [20] proposed a control allocation method for FTC of the pitch actuators. A virtual sensor/actuator scheme was applied in [21,22]. Montadher et al. presented Takagi-Sugeno fuzzy-based methods for FTC operating below the rated wind speed. Active FTC was presented in [17,23], and a model predictive control scheme was used for FTC in [24]. A compensation technique for input-constraint avoidance in the pitch control of a WT was proposed in [25]. Current research on actuator FTC proposed a dual, multivariable, model-free adaptive-control strategy with differential characteristics $[26,27]$ of Active FaultTolerant Control (AFTC).

Recent research presented the use of artificial intelligence to optimize the control of wind turbines. In [28], the authors proposed the use of a Neural Network to optimize key control parameters. In the same line, applied to FTC [29] applied Particle Swarm Optimization (PSO) to FTC to optimize the derating power in Inter-Turn Short Circuit (ITSC) faulty wind turbines. Both methodologies required access to the actual control loop parameters. Both proposed an adjustment of the generator control loop. The authors of [29] introduced two levels of FTC approach, one at the turbine level using a derating strategy, and a second approach at the wind farm level using an Optimal Power Dispatch Strategy (OPDS) combined with ITSC Fault Ride-Through (FRT). At the farm level, PSO was used to address proper references in all WTs. The basis of that research was similar to the proposed approach.

All existing research is focused on adjusting internal control loops in wind turbine control. Therefore, for a real application, it is required to obtain access to those control schemes, which are usually difficult to obtain, because they are confidential and protected by the Original Equipment Manufacturers (OEMs). The novelty of the proposed research relies in an implementation based on SCADA data and SCADA control set-points. This point is crucial for global scalability of the solution, since SCADA parameters are an open-access resource for any wind fleet operator.

Furthermore, instead of using the $5 \mathrm{MW}$ wind turbine model provided by NREL [30], the authors used scaled 2 MW WTG modelling with NREL-FAST.

Therefore, the presented research provides a unique FTC solution. It is based on fuzzy logic and can be implemented in the SCADA set-point control. The main goal of the research was to provide a methodology that allowed implementation in any wind turbine using the active power set-point on the SCADA.

This paper introduces a WT control strategy implemented in Simulink ${ }^{\circledR}$, and simulated with a 2 MW WT NREL-FAST model (corresponding to a Vestas V90 Turbine). Results analyses included both simulation and experimental results for a 2 MW V90 located in Spain. The manuscript provides an FTC approach analysing the impact on the wind turbine's performance.

\section{FAST}

Due to high production costs of WTs, Computer-Aided Engineering (CAE) has become fundamental to the wind energy industry due to its ability to obtain reliable and accurate simulations and results in the preproduction stage. The software that was utilized for the development of the project was OpenFAST, which is an open-source WT simulation tool designed by the NREL that computes the coupled dynamic response of WTs [31].

In this paper, a previous version of this software was utilized, FAST $v 8$, since it used the Simulink interface in which the control was designed, and is not yet available in the newest version of the software.

A Graphical User Interface (GUI) called FAST Tool Master integrated this software inMATLAB, and was used in this study due to its practicality [32]. This GUI offers a default control system already implemented in Simulink, and the corresponding modifications to design a FTC were utilized. Figure 3 shows the mentioned controller [33]. 


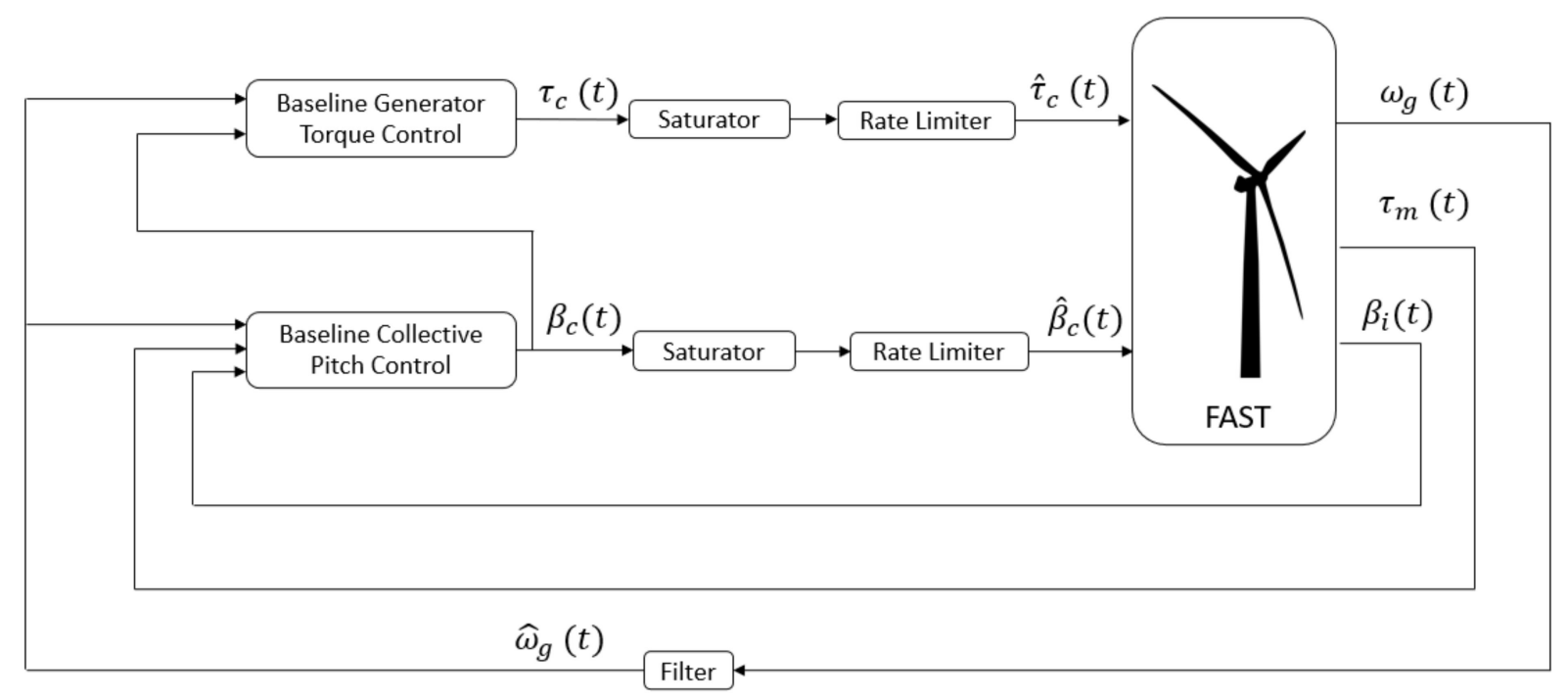

Figure 3. The control system implemented in FAST.

The controllers were designed to work independently from each other. Regarding the torque controller, its aim was to maximize the captured power from the wind for speeds below the rated wind speed by maintaining a constant (optimal) tip-speed ratio. This took place when the generator torque was proportional to the square of the filtered generator speed. On the other hand, the pitch control developed its roll above rated wind speeds, where the strategy was to vary the generator speed with the blade-pitch performance so that the electric power remained at the rated constant value.

\subsection{Pitch Control}

The controller's goal was to maintain constant generator torque and use collective blade-pitch angle control to regulate rotor speed in region $3[13,34]$. Therefore, we designed a pitch control system with the angular shaft rotation, $\Omega$, as the only Degree of Freedom (DOF) of the WT model. The system's equation of motion could be obtained from a simple free-body diagram of the drive train [30], which is expressed as:

$$
T_{\text {Aero }}-N_{\text {Gear }} T_{\text {Gen }}=\left(I_{\text {Rotor }}+N_{\text {Gear }}^{2} I_{\text {Gen }}\right) \frac{d}{d t}\left(\Omega_{0}+\Delta \Omega\right)=I_{\text {Drive-train }} \Delta \dot{\Omega}
$$

where $I_{\text {Drive-train }}$ is the drive-train inertia, $\Omega$ is the LSS rotational speed, $\Omega_{0}$ is the rated $\Omega$, $\Delta \Omega$ is the perturbation $\Omega$ about rated speed, $\Delta \Omega$ is the acceleration of $\Omega, t$ is the simulation time, $T_{\text {Aero }}$ is the Low Speed Shaft (LSS) aerodynamic torque, $N_{\text {Gear }}$ is the gear ratio, $T_{\text {Gen }}$ is the High Speed Shaft (HSS) torque, $I_{\text {Rotor }}$ is the rotor inertia, and $I_{G e n}$ is the generator inertia.

The controller aimed to keep the output power constant in region 3, making the generator torque inversely proportional to the generator speed. With $P_{0}$ as the rated power in region 3:

$$
T_{\text {Gen }}\left(N_{\text {Gear }}, \Omega\right)=\frac{P_{0}}{N_{\text {Gear }} \Omega_{0}}
$$

Following the same direction, the aerodynamic torque could also be described, assuming the rotor speed did not have an influence on it. With $P$ as the mechanical power and $\theta$ as the blade-pitch angle:

$$
T_{\text {Aero }}(\theta)=\frac{P\left(\theta, \Omega_{0}\right)}{\Omega_{0}}
$$


Applying a Taylor first-order approximation in Equations (2) and (3):

$$
\begin{gathered}
T_{\text {Gen }} \approx \frac{P_{0}}{N_{\text {Gear }} \Omega_{0}^{2}}-\frac{P_{0}}{N_{\text {Gear }} \Omega_{0}^{2}} \Delta \Omega \\
T_{\text {Aero }} \approx \frac{P_{0}}{\Omega_{0}}+\frac{1}{\Omega_{0}}\left(\frac{\partial P}{\partial \theta}\right) \Delta \theta
\end{gathered}
$$

Once these expressions were developed, a PID control was used to deal with the pitch perturbation, which can be expressed as:

$$
\Delta \theta=K_{P} N_{G e a r} \Delta \Omega+K_{I} \int_{0}^{t} N_{G e a r} \Delta \Omega d t+K_{D} N_{G e a r} \Delta \dot{\Omega}
$$

where $K_{P}, K_{I}$, and $K_{D}$ are the controller's proportional, integral, and derivative gains, respectively. When combining the above expressions, it can be observed that the PID controller would respond as a second-order system with frequency $\omega$ n and damping ratio $\zeta$. In [35], it was suggested to use values for these parameters of $0.1 \mathrm{~Hz}$; that is, $0.6 \mathrm{rad} / \mathrm{s}$; and $0.6-0.7$, respectively. This allowed us to avoid the derivative term and ignore the negative damping from the generator-torque controller.

Thus, once these parameters were fixed, to ensure the good performance of the controller, the aim was the selection of the adequate values for the proportional and integrative gains. Using the above expressions, it could be found that:

$$
K_{P}=\frac{2 I_{\text {Drive-train }} \Omega_{0} \zeta \omega_{n}}{N_{\text {Gear }}\left(-\frac{\partial P}{\partial \theta}\right)} K_{I}=\frac{I_{\text {Drive-train }} \Omega_{0} \omega_{n}^{2}}{N_{\text {Gear }}\left(-\frac{\partial P}{\partial \theta}\right)}
$$

\subsection{Torque Control}

The aim of the torque control was to maximize power captured below the rated wind speed, thus, maintaining peak $\mathrm{Cp}$ was required in addition to maintaining the optimum Tip-Speed Ratio (TSR). To fulfill this objective, the blade-pitch angles must be constant, where this angle was defined as the fine pitch angle, and the generator torque control was used to vary the speed of the turbine, ensuring said conditions [34]. Knowing that the generator torque varies with the square of the generator speed, it is trivial that:

$$
T_{\text {Gen }}=k \Omega^{2}
$$

where this constant is defined as:

$$
k=\frac{1}{2} \rho \pi R^{5} \frac{C_{P \max }}{\lambda_{o p t}^{3}}
$$

where $\rho$ is the air density, $R$ is the rotor radius, $\Omega$ is the generator speed, $C_{P \text { max }}$ is the maximum power coefficient, and $\lambda_{o p t}$ is the optimum TSR at a given blade-pitch angle.

Since $\rho$ and $R$ were constant values, the parameter $k$ was a function of $C_{P \text { max }}$, which at the same time depended on the TSR and the pitch angle. Therefore, in order to obtain the value for this parameter, an analysis of the power coefficient versus the TSR and blade-pitch angle surface was required. This surface could easily be obtained through simulation with rotor aerodynamic properties [34].

\subsection{MW Wind Turbine Model}

The analysis in this paper has been focused on a 2 MW WT in order to validate the results with experimental studies. Nonetheless, since there was not an aeroelastic model available to run the simulations in FAST for the selected rated power, a previous study to implement a model with these characteristics was required. In order to design this new model, the different NREL WindPACT Reference WTs with rated powers of $750 \mathrm{~kW}$, 
1.5 MW, $3 \mathrm{MW}$, and $5 \mathrm{MW}$ were analysed [36]. It was corroborated that all the distributed properties from the structure of the blade and tower, aerodynamics, etc., adjusted to either a linear or quadratic relationship with the blade length or the rated power.

Therefore, the scaling of the new WT was carried out through linear and quadratic interpolations between all the different NREL WindPACT Reference WTs. Moreover, the scale model was based on the Vestas V90, taking data from its technical specifications document and combining both the respective interpolations and adjusting the results to the available data. The details are reported in Table 2.

Table 2. Gross properties for the scaled $2 \mathrm{MW}$ wind turbine.

\begin{tabular}{cc}
\hline Parameter & $\mathbf{2 ~ M W}$ \\
\hline Rotor orientation, configuration & Upwind, three blades \\
Control & Variable speed, collective pitch \\
Rated tip and generator speed & $75 \mathrm{~m} / \mathrm{s}, 1680 \mathrm{rpm}$ \\
Shaft tilt, cone angle & $5^{\circ}, 0^{\circ}$ \\
Rotor diameter, hub diameter & $90 \mathrm{~m}, 4 \mathrm{~m}$ \\
Hub height & $111 \mathrm{~m}$ \\
Overhang & $4.443 \mathrm{~m}$ \\
Rotor mass & $54,000 \mathrm{~kg}$ \\
Nacelle mass & $77,000 \mathrm{~kg}$ \\
Tower mass & $271,000 \mathrm{~kg}$ \\
\hline
\end{tabular}

\section{Fault Detection and Tolerant Control Diagram}

To effectively introduce fault-tolerant control of a SCADA solution without entering into the actual control loops, the following architecture was proposed (Figure 4).

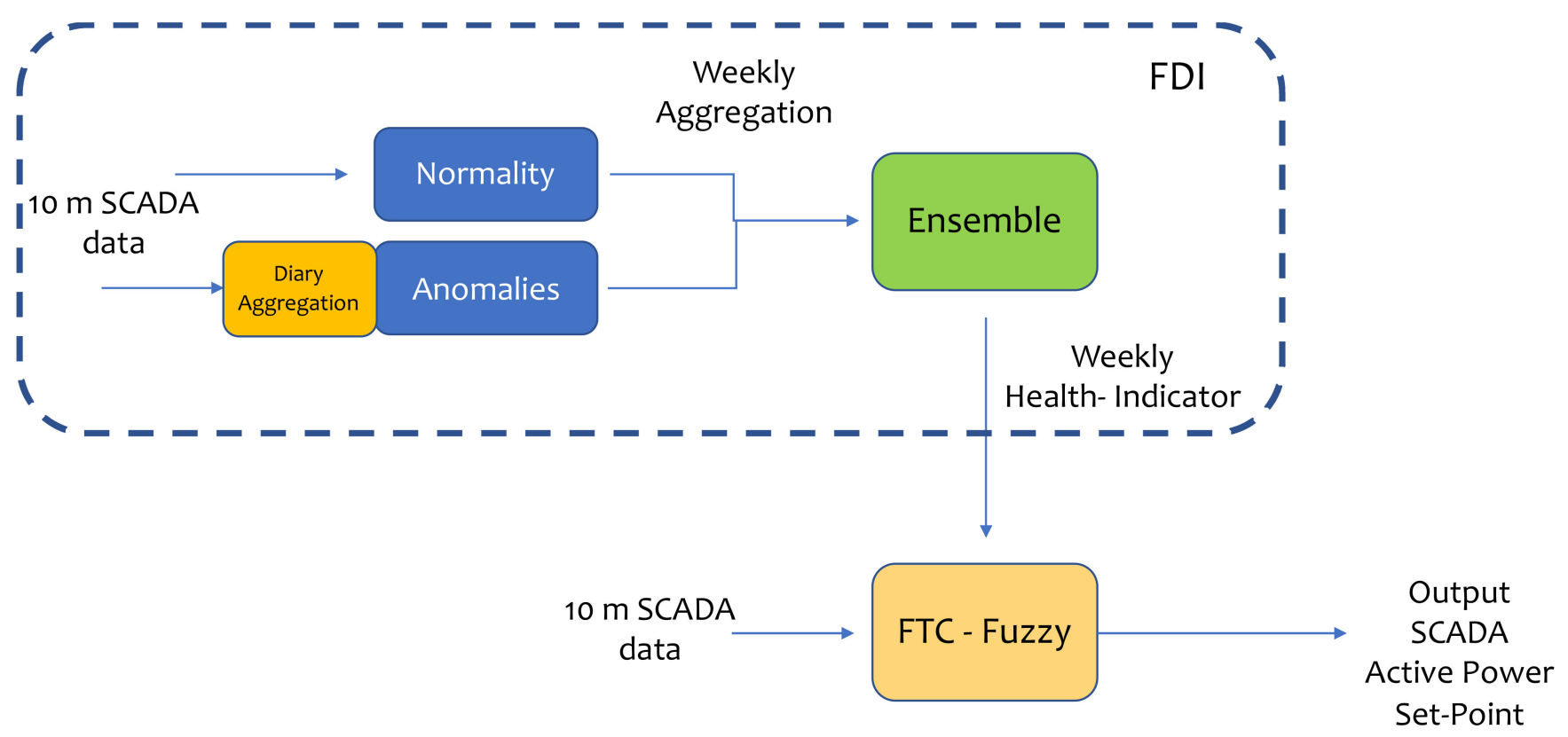

Figure 4. High level architecture diagram.

The main blocks conforming this Passive FTC were the Fault Detection Block and the Fault-Tolerant Control. The input was the standard $10 \mathrm{~min}$ SCADA data, usually acquired using an Open Platform Protocol (OPC). For the fault diagnosis, we proposed a solution combining Normality (Regression) Models and Anomalies using the ensemble learning introduced in Section 4. The fault diagnosis output was weekly health indicators that fed the fuzzy logic.

The Fault-Tolerant Control is introduced in Section 5. The inputs were health indicators 
(on a weekly basis) and $10 \mathrm{~min}$ SCADA data. The $10 \mathrm{~min}$ SCADA data was used to finetune the output during the weekly operation. The output was the real-time set-up point for the active power control.

\section{Health Indicators}

To determine early-stage failure conditions, unsupervised health indicators were used. Those indicators were obtained weekly and provided early-stage failure detection. Here, they were used as input for the Fault-Tolerant Control strategy. The health indicator was composed of a regressive and an anomalies algorithm. Then, ensemble learning was used to combine these two indicators, increasing sensibility and precision [15].

\subsection{Regressive Model}

Regressive modelling aims to determine the function that maps a set of inputs to a variable that can capture the status of the component under analysis. Normal operation data is used to train the algorithm, determining the relation between input and output for regular operating conditions. The trained model can then be used for checking deviations between predictions and measurements of the target sensor, thus determining abnormal conditions that can be related to failures.

In this work, the key target parameters were:

- Gearbox Bearing Average Temperature

- Gearbox Oil Average Temperature

The Root Mean Square Error (RMSE), Equation (10), was the chosen metric to compare the regression model with the actual parameter of the turbine. The regression algorithm used in the model was a Gradient Boosting Machine (GBM).

$$
R M S E=\sqrt{\frac{\sum_{i=1}^{N}\left(\text { Predicted }_{i}-\text { Actual }_{i}\right)^{2}}{N}}
$$

A GBM [37] is an iterative algorithm that uses base learners; e.g., decision trees, trained on the available dataset. At each iteration, an increased weight is assigned to the points of the dataset where the prediction error is large. Therefore, convergence is boosted towards the set of parameters that minimizes the chosen loss function.

The GBM Algorithm 1, as presented by Friedman (10.1214/aos/1013203451) is reported below.

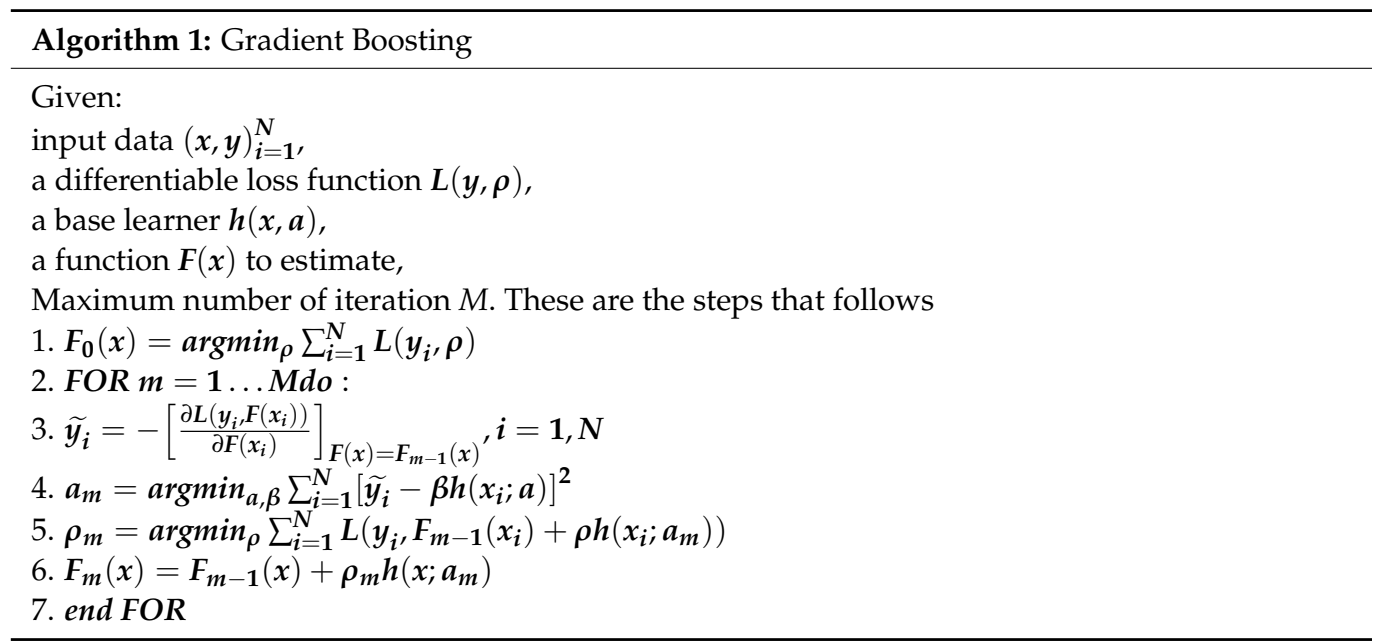

Various implementations of this algorithm are available; in this research, the scikitlearn library for the Python programming language was used [38]. The main parameters that were tuned during training of the algorithm were the number and depth of the estimators; i.e., the decision trees. 
For the construction of the regressive model, we used five different SCADA variables:

1. Ambient Temperature;

2. Wind Speed;

3. Active Power;

4. Generator Rotation Speed; and

5. Rotor Rotation Speed.

An important advantage of using a GBM is the vast degree of freedom that is left to the user. In fact, the algorithm is quite generic, and it works with an ample selection of loss functions. Moreover, a GBM typically obtains good results while maintaining limited training and predicting times.

\subsection{Anomaly Detection}

An isolation forest was the chosen anomaly detection algorithm. This was used to compare the status of each turbine with the rest of the wind farm, to determine whether one or more turbines were behaving differently than the others.

The algorithm is based on decision trees, and was thoroughly described by Liu et $\mathrm{Al}$ [39]. An isolation forest classifies as anomalies all those points lying on regions of the feature space characterized by low point density, typically corresponding to the edges of the data distribution. To achieve this objective, multiple fully developed trees, meaning trees characterized by single-element nodes, were trained. An important characteristic of an isolation forest is that splits of the data are made on a random basis. By using random splits, anomalies naturally tend to separate from the bulk of the data.

The anomaly score that was defined for the isolation forest is detailed in Equation (10), where $E(h(x))$ corresponds to the average of the path length $h(x)$ required to isolate a given instance. The denominator $c(n)$ is the average path length of an unsuccessful search in the Binary Search Tree. Instances in which the $s$ value approaches 1 are considered anomalies; if $\mathrm{s}$ is less than 0.5 , then these points are considered as normal instances. Finally, if $\mathrm{s}$ is close to 0.5 for all points in the dataset, it can be concluded that no anomalies are present in the dataset.

$$
s(n, x)=2^{-\frac{E(h(x))}{c(n)}}
$$

The scikit-learn implementation for the Python programming language was used in this research [38]. Of the available hyperparameters, the number of estimators, contamination, and maximum number of samples were tuned during the training phase.

The input variables for the algorithm were the following:

1. Rotor Rotation Speed;

2. Ambient Temperature;

3. Gearbox Oil Temperature; and

4. Gearbox Bearing Temperature.

The results of the anomaly-detection algorithm were post-processed to obtain a fault indicator. This was defined as the ratio of anomalies for a given turbine over the total amount instances in the time period defined for the analysis; i.e., one week in our case. Equation (12) shows the definition of the anomaly indicator; this fraction can then be used to compare a given turbine with the rest of the wind farm, determining those turbines that have a higher percentage of anomalies.

$$
\text { Anomaly rate }=\frac{n_{\text {anomalies }}}{n_{\text {total }}}
$$

\subsection{Ensemble Learning}

Ensemble learning was used according to the methodology described in [15]. Normality and anomalies results were combined into a composed indicator, with the objective of obtaining better predictions. To build a valuable ensemble, complementary and nonredundant indicators were used. The RMSE indicator and anomaly indicator were combined 
through a rolling windowed average with a size of one week. Following Algorithm 2 introduces how the ensemble indicator is obtained.

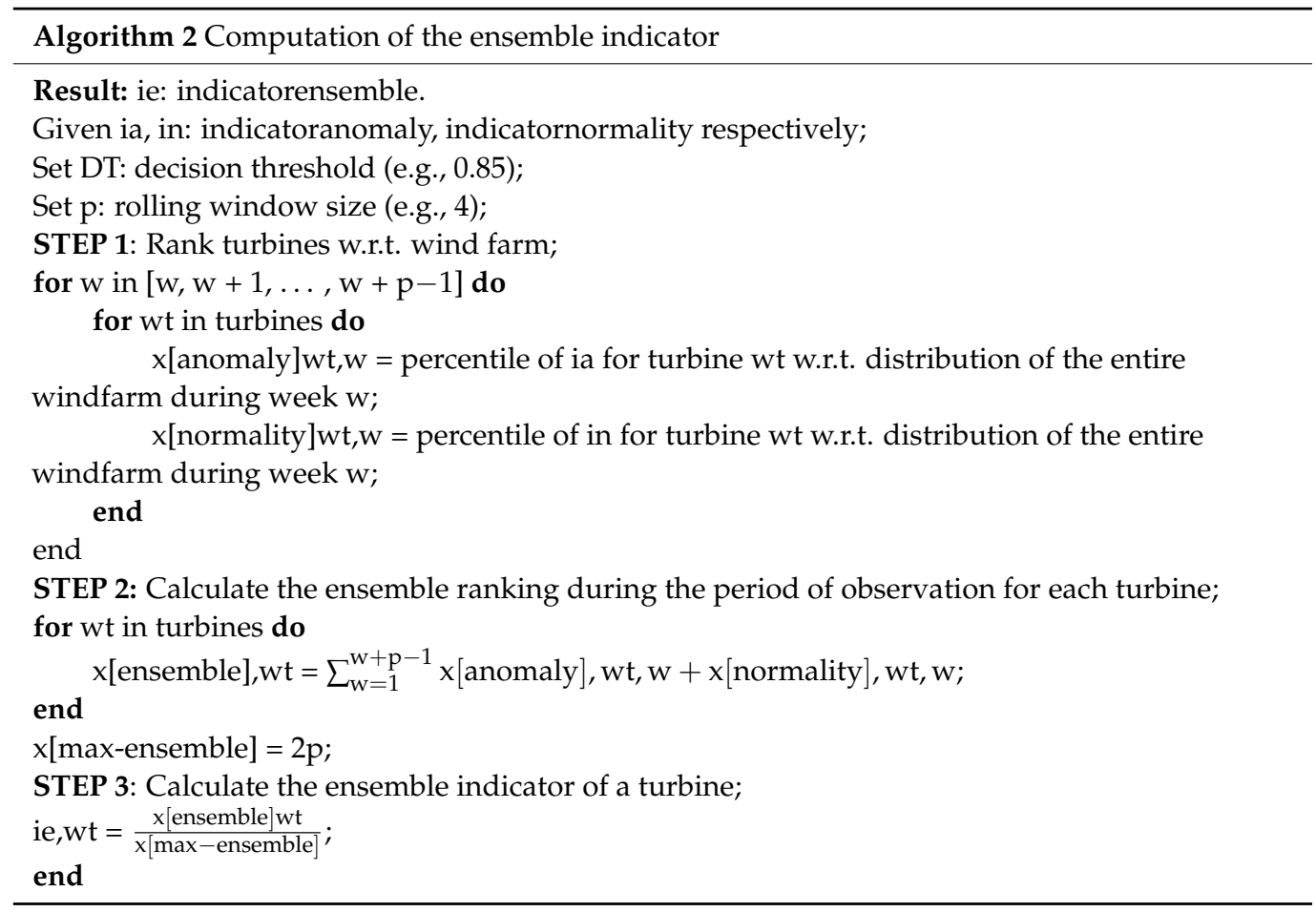

\section{Fault-Tolerant Control}

In this paper, two different strategies were studied and implemented in FAST. Both focused on a health indicator for the key components of the gearbox, which was named "merge". This indicator was developed by the SMARTIVE company and ranged from 0 to 1 , representing the turbine operating with no damage to the gearbox components and operating in total fault status, respectively. This value was computed weekly for each WT.

The first control strategy used proportional derating with the merge, and the second one used a fuzzy logic control that outputted the appropriate limitation so as to ensure a safe operation by adjusting it to the needs of the turbines in real time.

The derating strategy was implemented by externally adjusting the power set-point; however, due to the constraints of the Simulink model, the limitation in this study was carried out inside the controller by including a gain factor after the torque saturation block and in the generator speed measurement, as shown in Figure 4. It was estimated that approximately $60 \%$ of the total power limitation was destined to decrease the generator speed, while the rest was transformed in the generator torque reduction.

According to [40], a load mitigation of 10 to $20 \%$ may bring considerable savings for the main components of the gearbox, so the following FTC strategies were based on this idea.

\subsection{Proportional Controller}

This is a simple first proposal for a FTC in which the power limitation is decided as a function of the merge. A MATLAB function was defined where, for wind speeds greater than $10 \mathrm{~m} / \mathrm{s}$, the output generated a gain value representing the power limitation, which follows the expression below:

$$
f(x)=\left\{\begin{array}{r}
1 \text { if } x<0.5 \\
1.3-x \text { if } x \geq 0.5
\end{array}\right.
$$


where $x$ represents the health status indicator, ranging from 0 to 1 . With this, the minimum limitation when the merge indicated a value of 0.5 resulted in an output value of 0.8 , which was associated with a $20 \%$ reduction. In this way, the maximum available limitation was $70 \%$, which was applied when the merge reached unity. Greater deratings would make no physical sense, since they would involve shutting down of WT.

\subsection{Fuzzy Logic Controller}

To obtain a smoother response and operate the turbines more effectively, a fuzzy logic controller was employed with the aim of adjusting to the needs of the turbines in real time. With this technique, it was possible to provide a more accurate limitation as a function of the wind and the gearbox oil and bearing temperatures, thus avoiding excessive power derating and increasing the production. Fuzzy logic can be implemented quickly and requires no actual training, which provides an optimal output in terms of cost benefits.

Our technique consisted of two different fuzzy logic controllers, as shown in Figure 5, with the first having as inputs the actual wind speed and the merge indicator, while the second only used a single input related to the gearbox bearing temperature. Two different controllers were set so they can work independently from each other, thus increasing the overall reliability of the FTC. Moreover, the wind-merge controller aimed to limit the output power, whereas the temperature controller was designed in such way that, if the temperature fell below a specific value, the output corrected the actual limitation by decreasing it, and therefore prevented the controller from an excessive and inappropriate down-regulation. In this direction, if the temperature is increasing, the global limitation also should increase so as to achieve the aim of bringing the gearbox down to lower temperatures.

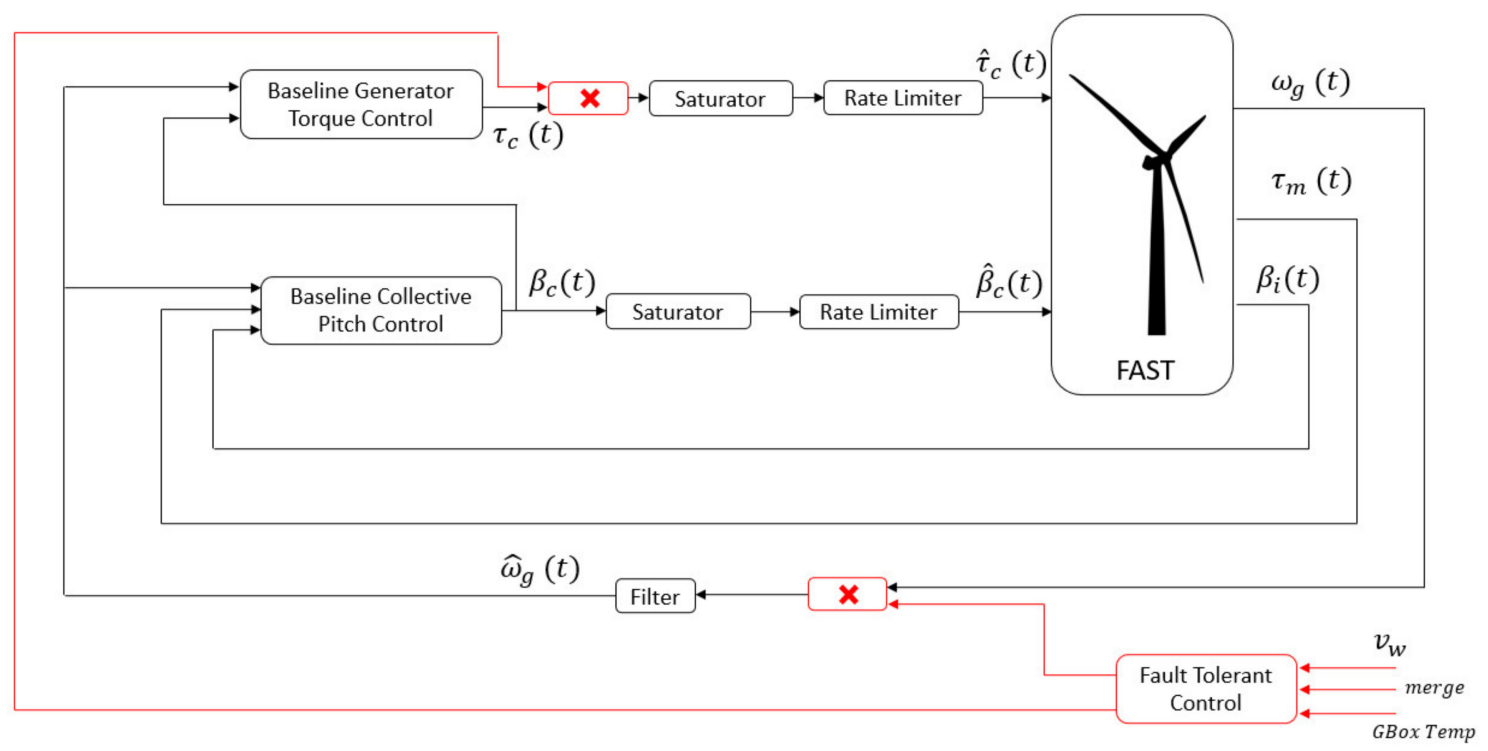

Figure 5. The proposed Fault-Tolerant Control.

Finally, when combined, a saturation block was set with an upper limit of the unity and a lower limit of 0.3 , meaning that the turbine would not be derated more than $70 \%$, following the same scheme as in the proportional controller.

As can be observed in Figure 6, a sine wave was employed to simulate the behaviour of the gearbox bearing temperature with time, and is described as expressed below:

$$
T(t)=T_{0}+A \sin \left(\frac{2 \pi}{P} t\right)=65+10 \sin \left(\frac{2 \pi}{20} t\right)\left[{ }^{\circ} C\right]
$$

where $T_{0}$ is the mean bearing temperature, $A$ is the wave amplitude, and $P$ is the period expressed in seconds. 


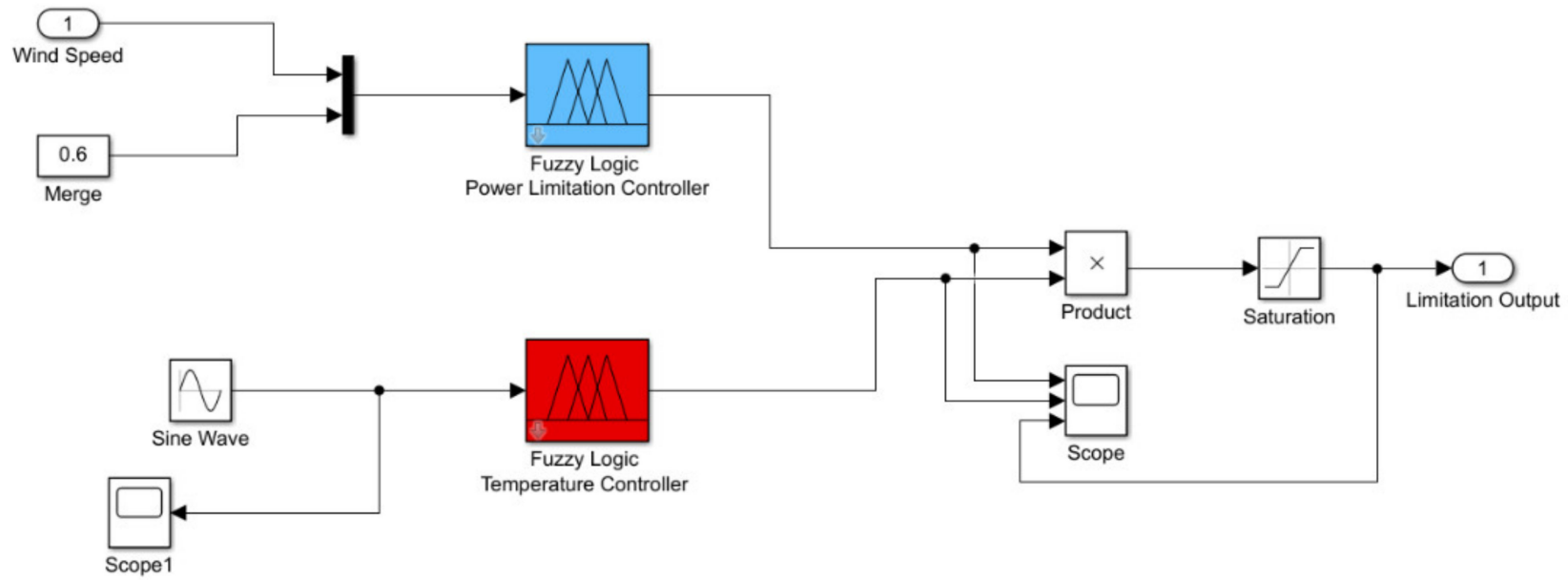

Figure 6. Fuzzy logic implementation in the Simulink control model.

The fuzzy membership functions (MF) were designed with the MATLAB Fuzzy Logic Toolbox in order to be practical and effective. Gaussian and saturated Gaussian MF were employed to ensure smooth transitions (Figure 7). The actual response of the control, torque, speed, and power related to the wind turbine was linear. Therefore, Gaussian membership functions worked well on data probabilities and statistics, which was the actual input coming from the ensemble learning [41].

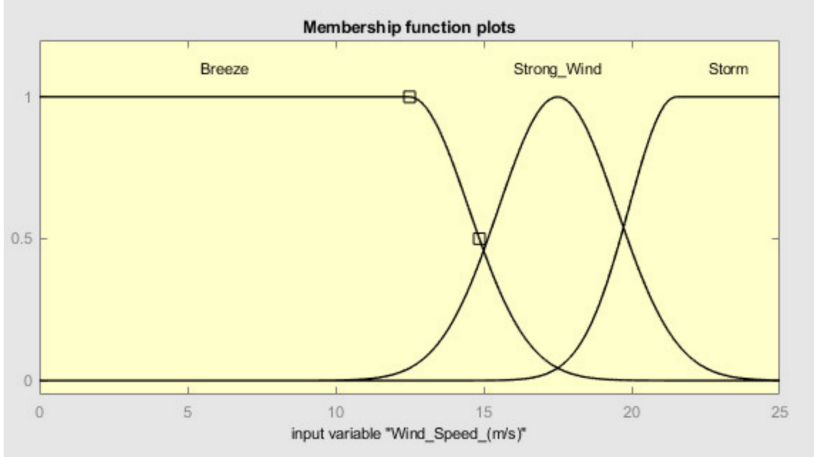

(a)

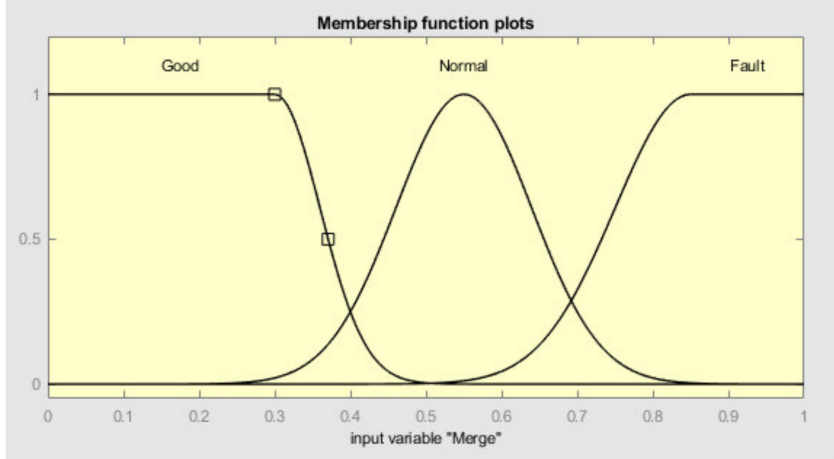

(b)

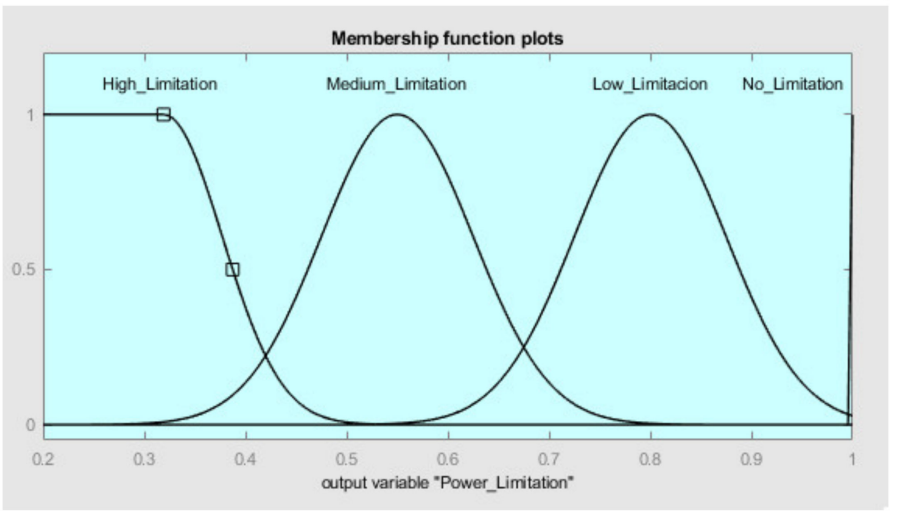

(c)

Figure 7. Input and output MF for the wind-merge controller: (a) wind speed MF; (b) merge indicator MF; (c) power limitation MF.

Finally, the MFs were combined together with the fuzzy rules. These rules infer numerical output based on numerical input variables in such way that if $\mathrm{x}$ is $\mathrm{A}$ and $\mathrm{y}$ is $B$, then $\mathrm{z}$ is $\mathrm{C}$, where $\mathrm{A}, \mathrm{B}$ and $\mathrm{C}$ are represented as linguistic variables using fuzzy 
sets depending on the defined MF, which were designed following logic criteria based on common sense and adjusting the final results so as to obtain smooth transitions. The associated surface is shown below (Figure 8).

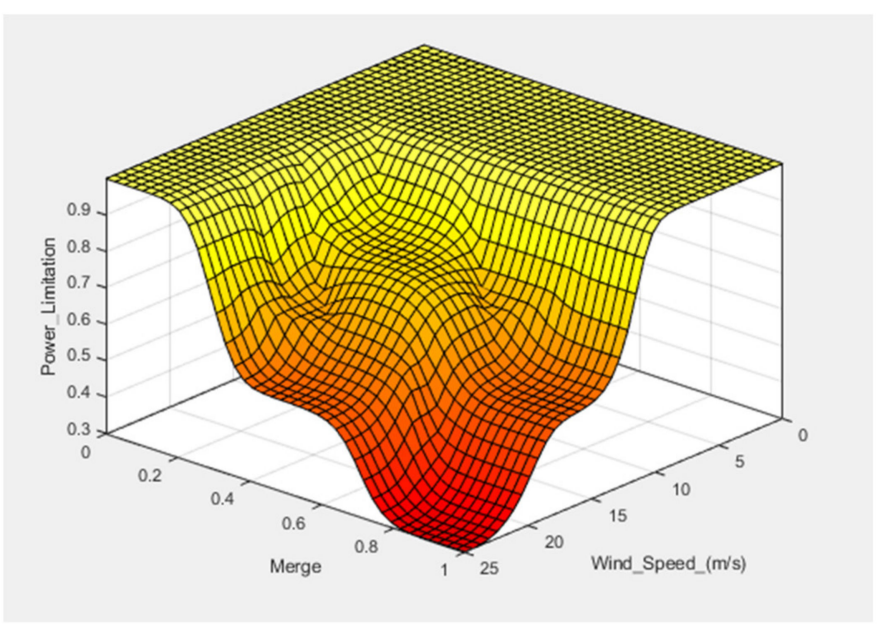

Figure 8. Surface associated with the wind-merge controller.

On the other hand, regarding the temperature controller, when applying the defined sine wave in Equation (2), the behaviour in Figure 9 was shown.

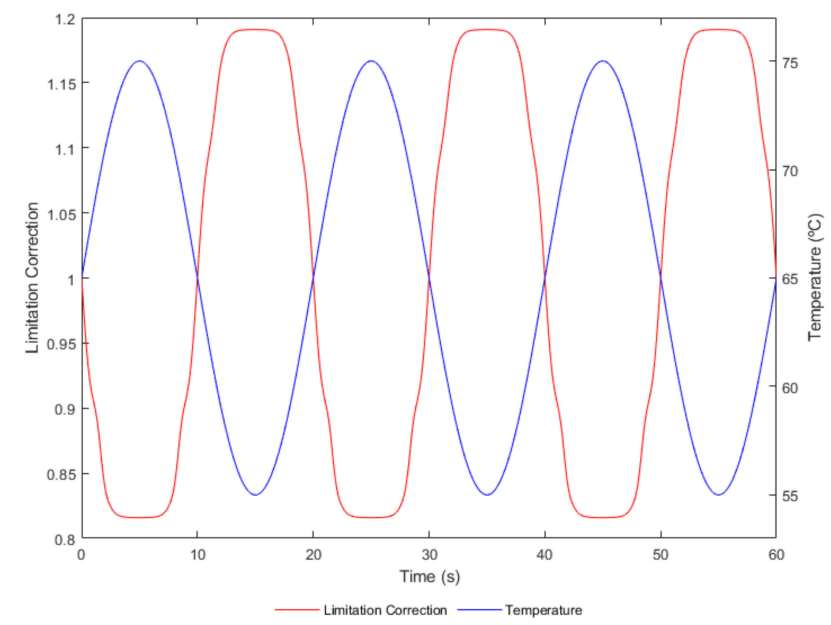

Figure 9. Surface associated with the wind-merge controller.

\section{Results}

The analysis in this paper was validated through simulations in NREL-FAST, and also by implementing the power-derating control strategy in actual wind turbines and observing the response obtained experimentally.

\subsection{Simulation Results}

Multiple simulations were conducted in order to analyse the effect of the powerderating strategy in a $2 \mathrm{MW}$ WT model, taking into consideration the generator speed and torque reduction, as well as the effects on the blade and tower moments and deflections.

All the simulations were run at a constant steady wind speed of $15 \mathrm{~m} / \mathrm{s}$ for $60 \mathrm{~s}$, and applied the required power limitations so that the WT worked at $100 \%, 80 \%, 65 \%$, and $50 \%$ of the rated power. The results obtained with these limitations are shown in Figure 10. 


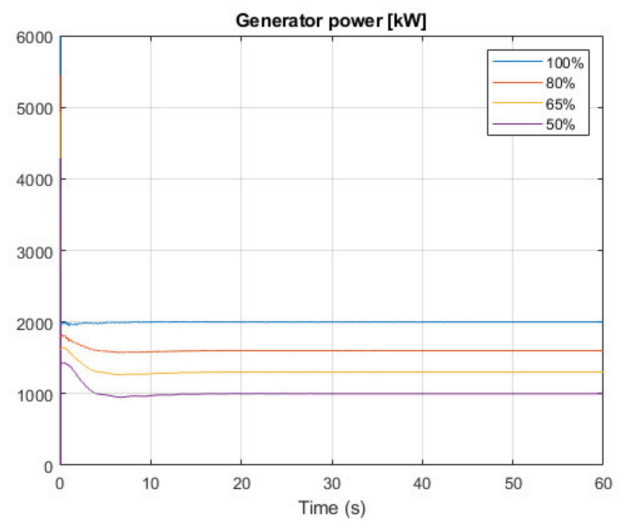

(a)

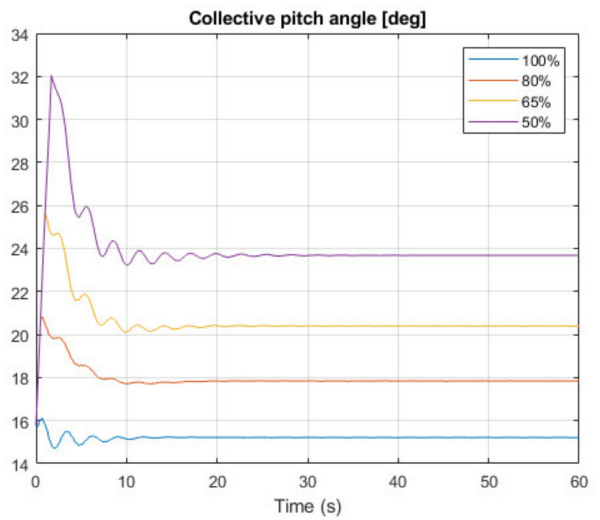

(c)

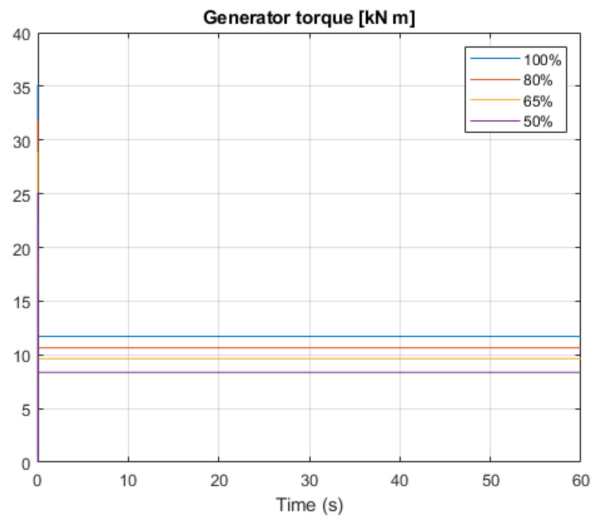

(b)

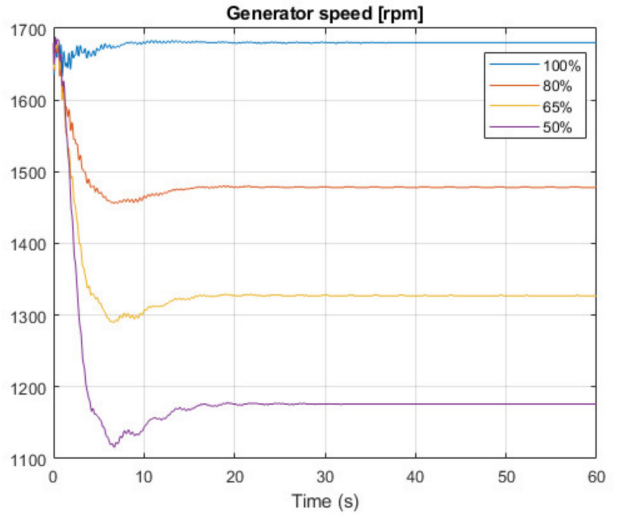

(d)

Figure 10. Simulation responses with different power limitations: (a) generator power; (b) generator torque; (c) collective pitch; (d) generator speed.

As can be observed in the above figures, the blade-pitch angle increased with the limitation applied. In pitch control, an increase of the pitch angle resulted in a decrease of the angle of attack. Therefore, the lift and drag coefficients also decreased, and with them, the total lift and drag forces. In the end, this resulted in decreased rotor thrust, and hence a drop in the produced power, achieving the original aim, which can be observed in the reduction of the generator torque and generator speed.

Moreover, Figure 11 shows the blade's in-plane deflection (along the $\mathrm{x}$ axis) and out-of-plane deflection (along the $y$ axis) together with the tower top fore-aft and sideside deflections.

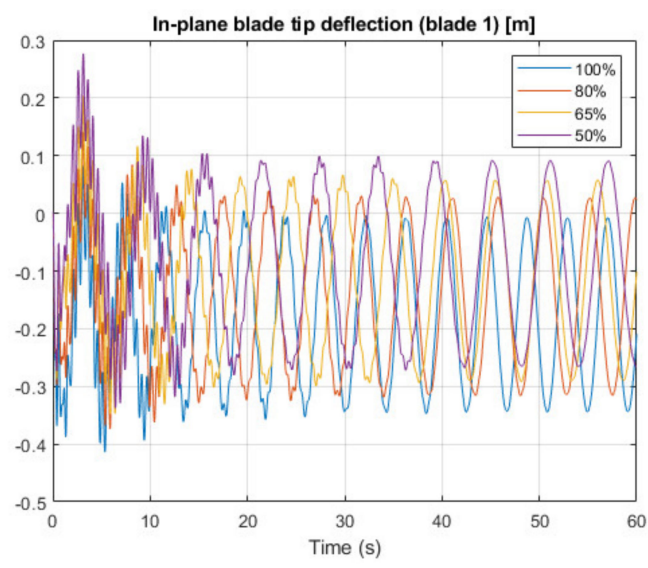

(a)

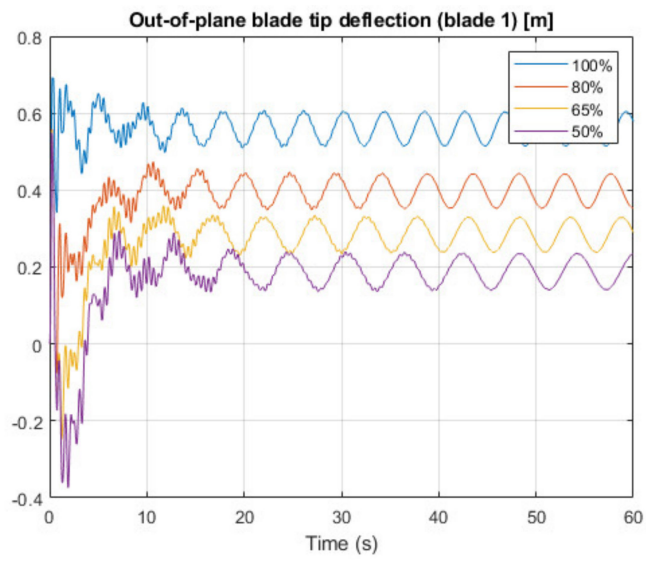

(b)

Figure 11. Cont. 


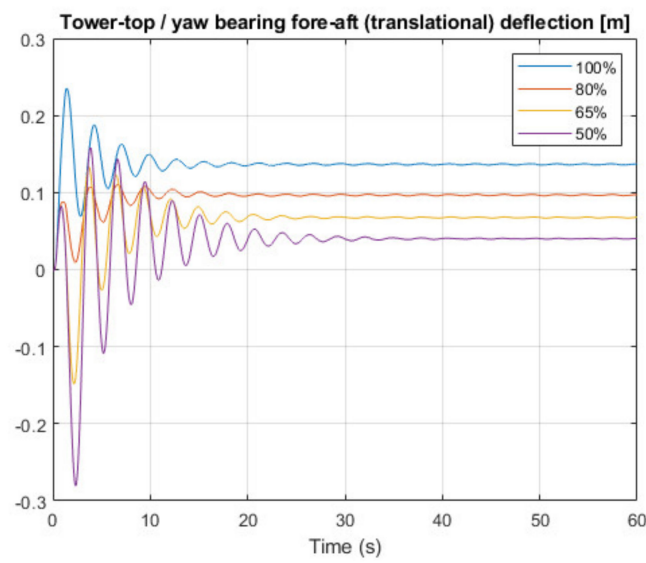

(c)

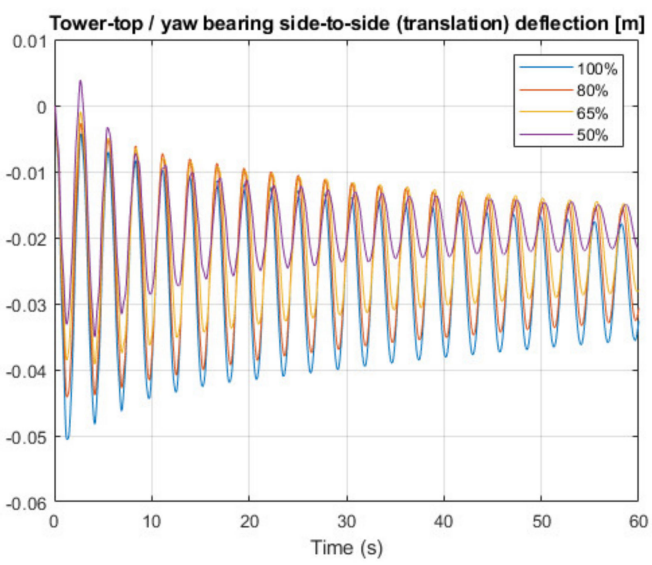

(d)

Figure 11. Simulation efforts for different power limitations: (a) in-plane blade tip deflection; (b) out-of-plane blade tip deflection; (c) tower top fore-aft deflection; (d) tower top side-side deflection.

It can be easily appreciated that with the power limitation, the tower and blade tip deflections diminished with no exceptions, for either the mean value or its amplitude. In the case of the in-plane deflection shown in Figure 10, it can be observed that, at lower power outputs, it oscillated more around its non-deflected position; that is, the mean value of the sine wave approached a null value of deflection. Due to the decrease of the aerodynamic loads by increasing the pitch angle, it was apparent that the deflections must be in accordance with said reduction of deflections (Figure 12).

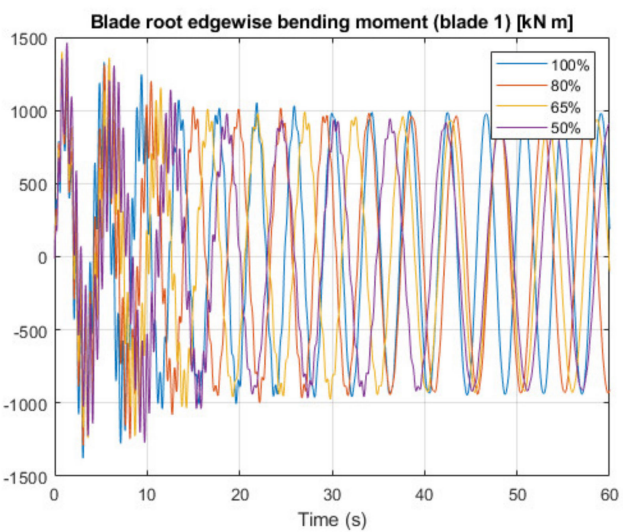

(a)

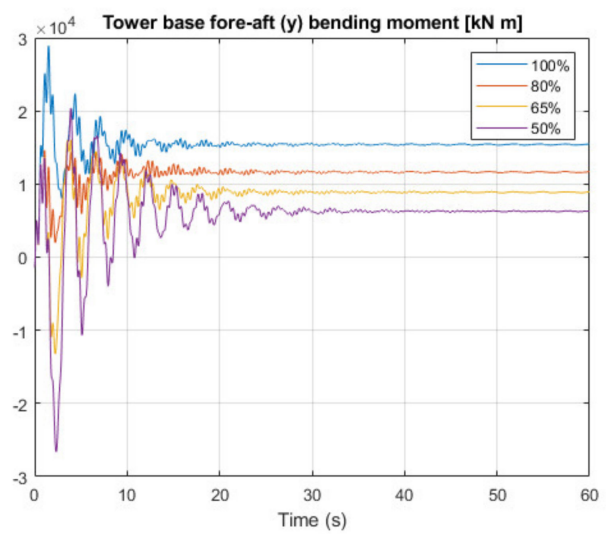

(c)

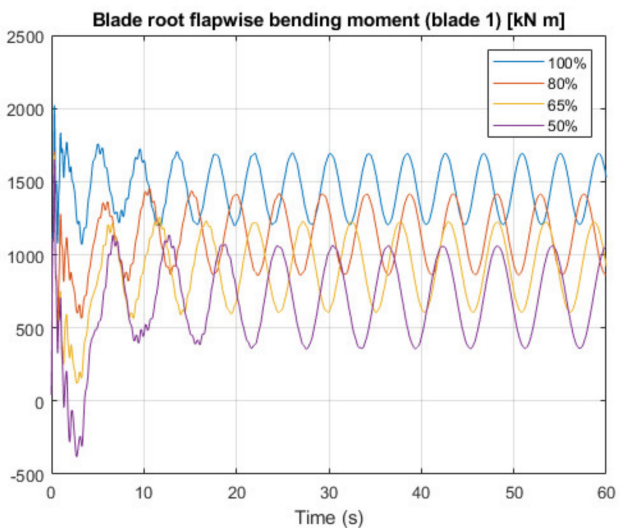

(b)

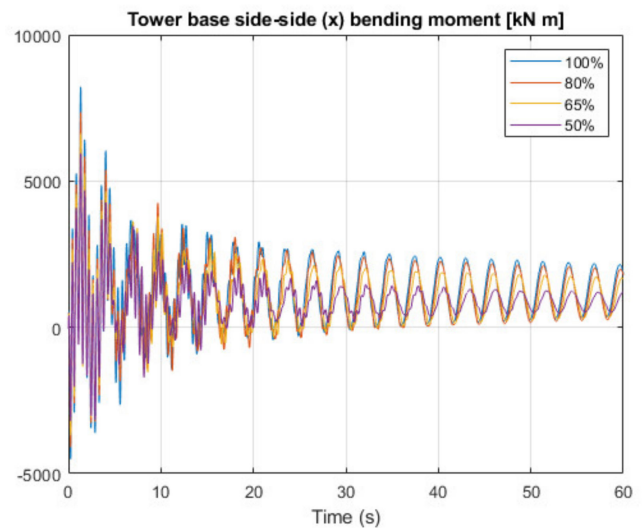

(d)

Figure 12. Simulation efforts at a different power limitations: (a) blade root edgewise moment; (b) blade root flapwise bending moment; (c) tower base fore-aft bending moment, (d) tower base side-side bending moment. 
The results obtained demonstrated the direct consequences of the power derating and its associated increase of the blade-pitch angle (Figure 10c). However, it can also be concluded that, by slowing down the generator speed, the oscillatory blade stresses; that is, the edgewise and flapwise bending moments, we observed a decrease in the wave frequency, which involved a better fatigue resilience, and hence extended its lifetime.

Matching failure analysis with Fault-Tolerant Control, Table 3 shows the output once failure was identified by the ensemble learning. The ensemble combined information originating from anomalies and normal deviations of the Gearbox_Temp_avg and Gear_Oil_Temp_avg. Therefore, once the ensemble output reached 70\%, the control began derating power, reducing shaft torque and speed. This study was carried out considering a constant steady wind speed of $15 \mathrm{~m} / \mathrm{s}$.

Table 3. Ensemble input and FTC simulation output.

\begin{tabular}{ccccc}
\hline Merge & Power Derating & Torque Reduction & $\begin{array}{c}\text { Generator Speed } \\
\text { Reduction }\end{array}$ & Pitch Angle $\left(^{\circ}\right.$ ) \\
\hline 0.75 & $10 \%$ & $4 \%$ & $6 \%$ & 16.43 \\
0.80 & $20 \%$ & $9 \%$ & $12 \%$ & 17.84 \\
0.85 & $30 \%$ & $15 \%$ & $18 \%$ & 19.47 \\
0.90 & $40 \%$ & $21 \%$ & $24 \%$ & 21.40 \\
0.95 & $50 \%$ & $29 \%$ & $30 \%$ & 23.68 \\
\hline
\end{tabular}

\subsection{Experimental Results}

For the experimental results, real-time data was acquired using a direct Open Platform Communication (OPC) connection with Vestas On-line in a Vestas V90 2 MW operating in Spain. The data analytics were done using algorithms written in the Python programming language [15] adjusted for the gearbox and implementing an ensemble combining the Root Mean Square Error (RMSE) of the normality model and anomalies obtained when comparing data of the entire wind farm. The resulting heat map clearly shows how Wind Turbine SG07 was the most critical.

The merged indicator indicated the health status of the component in a scale between 0 and 1 , with 0 meaning healthy and 1 indicating a fault status. Critical failures were above 0.8 in the merge. For this specific case, a RMSE deviation of $6^{\circ}$ from the expected oil temperature and anomalies of excessive temperatures were observed, as reflected in Figures 13 and 14.

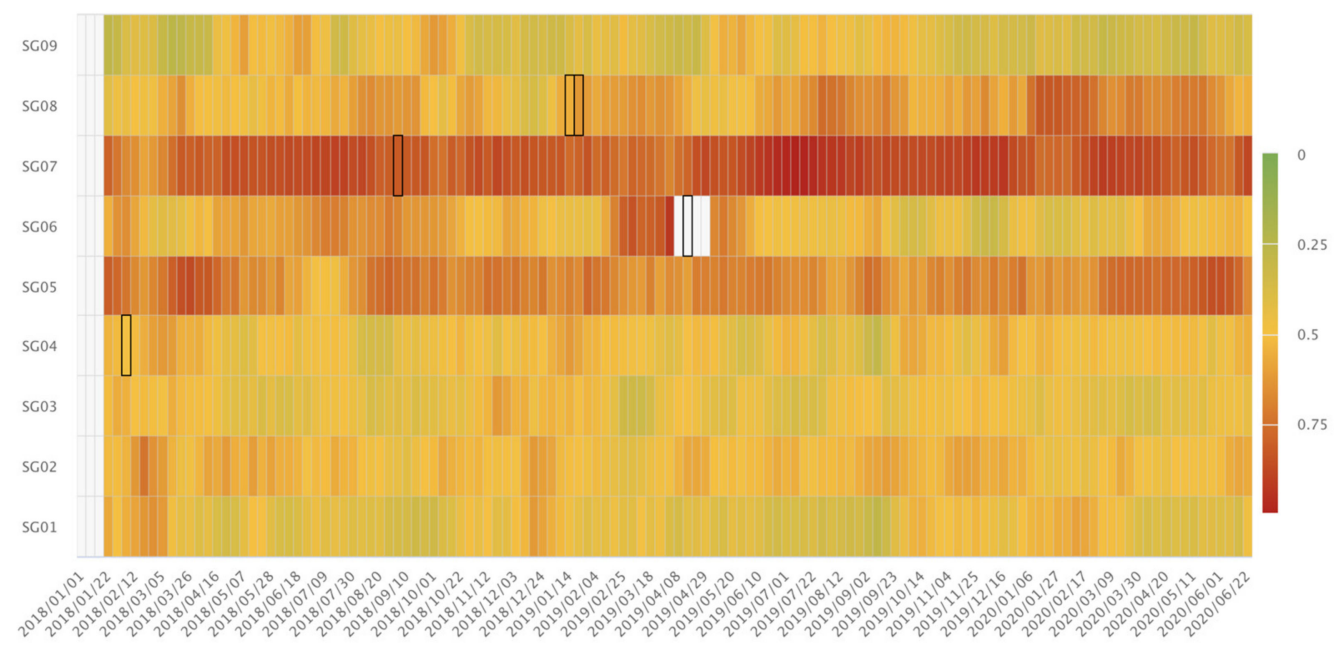

Figure 13. Merged weekly indicator (wind farm view). 


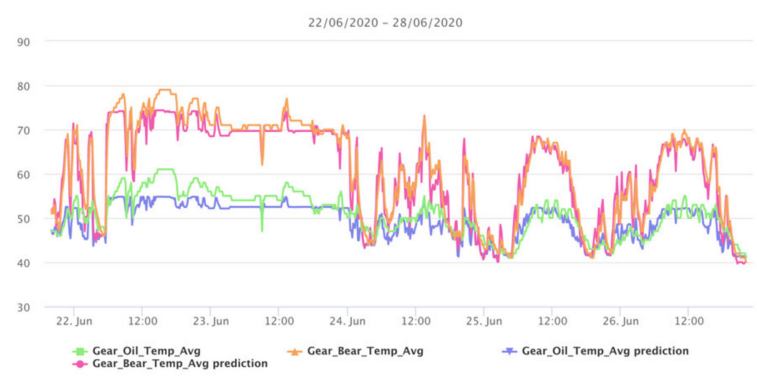

(a) Regressive modelling

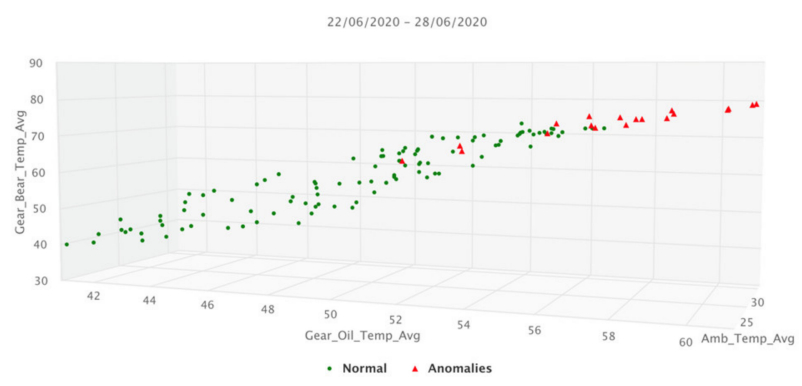

(b) 3D anomalies representation

Figure 14. AI results representation.

In Figure 13, the regressive model and the anomalies are shown. Notice that the main deviations occurred on 22 June in the afternoon. The deviation reached $6{ }^{\circ} \mathrm{C}$. On 23 June, power limitation was applied, as shown in Figure 14.

Figure 15a shows the performance response once the limitation was in place; the figure shows a comparison with the wind farm average value of the oil temperature. This average was obtained using the real-time value of each wind turbine for that instance. Once the limitation was in place, the temperature clearly decreased $5{ }^{\circ} \mathrm{C}$, reducing the excessive heating of the gearbox. Once the limitation was removed, on 23 July at 14:40, the deviation appeared again.

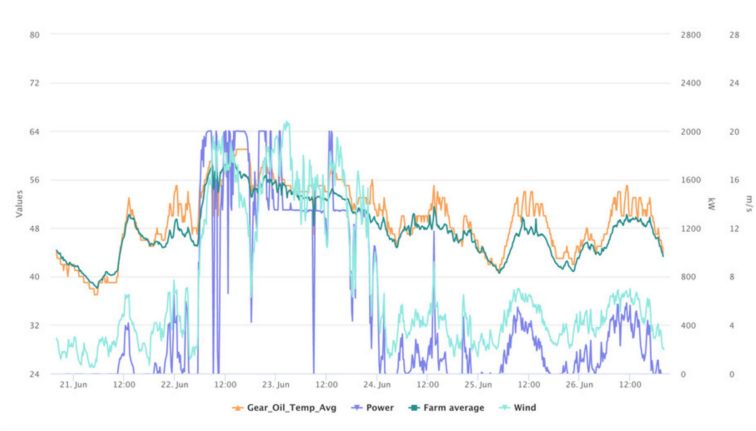

(a) Power reduction response of Gear_oil temp

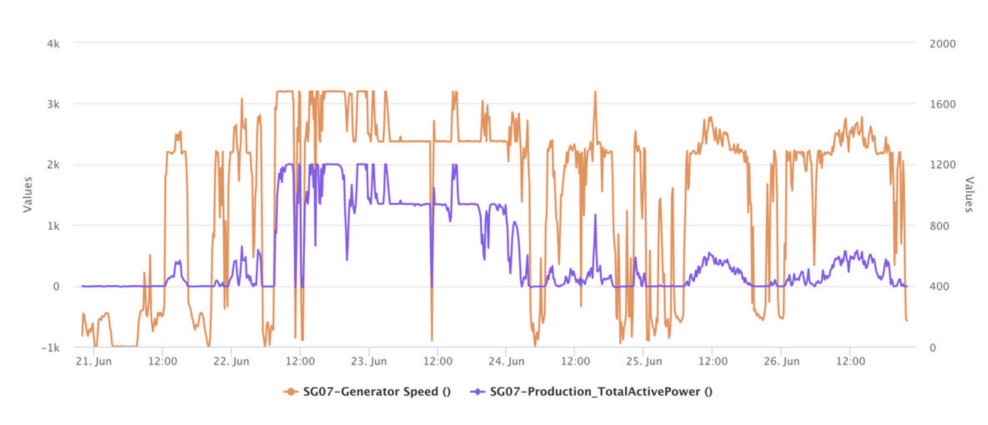

(b) Power reduction response of generator speed

Figure 15. Real-time data response applying power reduction.

Figure $15 b$ correlates with the expected speed, and therefore the torque, response obtained in Figure 10d for a power limitation of $65 \%$. Therefore, the models and expected responses were perfectly validated.

\section{Discussion and Conclusions}

The manuscript has presented FTC methodology that can be implemented in any WT using the SCADA system.

The proposed solution combined health indicators and real-time $(10 \mathrm{~min})$ data to adjust the fuzzy logic response. The presented health indicators were obtained by means of regressive modelling and anomalies analysis, and both indicators were combined using ensemble learning.

This research was based on an NREL-FAST simulation. The 2 MW WT model was presented, and the results were compared with actual wind turbine validation on a V90 2 MW wind turbine located in a Spanish wind farm. Therefore, using NREL-FAST simulations demonstrated a positive response, reducing the stresses on main components thanks to the active power derating control strategy.

The effort reduction was determined to be $\frac{1}{2}$ of the power reduction of torque, and the expected stresses on the tower and blades were also proportionally reduced once the active 
power was reduced. Therefore, the life expectancy was increased, and the operation of the turbine was warrantied.

The experimental results demonstrated the positive effects of the power-derating control strategy.

Therefore, by combining AI for health analysis and fuzzy rules, an operator can control the efforts and the stress on the wind turbine, allowing them to keep the operation secure, especially with high winds. The combination of weekly prediction with real-time data allows the adjustment of the active power response, optimizing the energy produced.

Author Contributions: Conceptualization, J.C. and A.L.; methodology, J.C.; software, A.L., M.B.; validation, J.C., A.L. and M.B.; formal analysis, A.L.; investigation, J.C., A.L. and M.B.; resources, J.C.; data curation, M.B. and A.L.; writing — original draft preparation, J.C., A.L. and M.B.; writing-review and editing, J.C., A.L. and M.B.; visualization, J.C.; supervision, J.C.; project administration, J.C.; funding acquisition, J.C. All authors have read and agreed to the published version of the manuscript.

Funding: This work has been partially funded by the Spanish Centro para el Desarollo Tecnológico Industrial, grant number CDTI-IDI 20191294; the Agència de Gestió d'Ajuts Universitaris i de Recerca (AGAUR), grant number 2017 SGR 1348; and Ministerio de Ciencia e Innovación, grant number PID2020-120314RB-I00.

Institutional Review Board Statement: Not applicable.

Informed Consent Statement: Not applicable.

Data Availability Statement: Not applicable.

Acknowledgments: Thanks to SMARTIVE company for the access to the Data.

Conflicts of Interest: The authors declare no conflict of interest.

\section{Abbreviations}

$\begin{array}{ll}\text { AFTC } & \text { Active Fault-Tolerant Control } \\ \text { DOF } & \text { Degree of Freedom } \\ \text { FAST } & \text { Fatigue, Aerodynamics, Structures and Turbulence } \\ \text { FTC } & \text { Fault-Tolerant Control } \\ \text { HSS } & \text { High Speed Shaft } \\ \text { IPC } & \text { Individual Pitch Control } \\ \text { ITSC } & \text { Intern Turn Short Circuit } \\ \text { LSS } & \text { Low Speed Shaft } \\ \text { MF } & \text { Membership Functions } \\ \text { MPPT } & \text { Maximum Power Point Tracking } \\ \text { NREL } & \text { National Renewable Energy Laboratory } \\ \text { OPC } & \text { Open Platform Communication } \\ \text { OPDS } & \text { Optimal Dispatch Strategy } \\ \text { PFTC } & \text { Passive Fault-Tolerant Control } \\ \text { PI } & \text { Proportional-Integral } \\ \text { PID } & \text { Proportional-Integral-Derivative } \\ \text { PSO } & \text { Particle Swarm Optimization } \\ \text { RMSE } & \text { Root-Mean-Square Error } \\ \text { SCADA } & \text { Supervisory Control and Data Acquisition } \\ \text { TSR } & \text { Tip-Speed Ratio } \\ \text { WT } & \text { Wind Turbine }\end{array}$

\section{References}

1. Renewable Energy Institute, "Statistics Global Energy". Available online: https://www.renewable-ei.org/en/statistics/ international/ (accessed on 12 August 2021).

2. Sheng, S. Report on Wind Turbine Subsystem Reliability—A Survey of Various Databases; National Renewable Energy Laboratory: Golden, CO, USA, 2013. 
3. Reder, M.D.; Gonzalez, E.; Melero, J.J. Wind turbine failures-tackling current problems in failure data analysis. In Journal of Physics: Conference Series; IOP Publishing: Bristol, UK, 2016; Volume 753, p. 072027.

4. Faulstich, S.; Hahn, B.; Tavner, P.J. Wind turbine downtime and its importance for offshore deployment. Wind Energy 2011, 14, 327-337. [CrossRef]

5. Statista. 2021. Available online: https://www.statista.com/statistics/268363/installed-wind-power-capacity-worldwide/ (accessed on 12 August 2021).

6. Gao, Z.; Liu, X. An overview on fault diagnosis, prognosis and resilient control for wind turbine systems. Processes 2021, 9, 300. [CrossRef]

7. Hart, E.; Clarke, B.; Nicholas, G.; Amiri, A.K.; Stirling, J.; Carroll, J.; Dwyer-Joyce, R.; McDonald, A.; Long, H. A review of wind turbine main bearings: Design, operation, modelling, damage mechanisms and fault detection. Wind Energy Sci. 2020, 5, 105-124. [CrossRef]

8. Rashid, H.; Khalaji, E.; Rasheed, J.; Batunlu, C. Fault Prediction of Wind Turbine Gearbox Based on SCADA Data and Machine Learning. In Proceedings of the 10th International Conference on Advanced Computer Information Technologies (ACIT) Advanced Computer Information Technologies (ACIT), Deggendorf, Germany, 16-18 September 2020.

9. Habibi, H.; Howard, I.; Simani, S. Reliability improvement of wind turbine power generation using model-based fault detection and fault tolerant control: A review. Renew. Energy 2019, 135, 877-896. [CrossRef]

10. Acho, L.; Rodellar, J.; Tutivén, C.; Vidal, Y. Passive Fault Tolerant Control Strategy in Controlled Wind Turbines. In Proceedings of the 3rd Conference on Control and Fault-Tolerant Systems (SysTol), Barcelona, Spain, 7-9 September 2016.

11. Pozo, F.; Vidal, Y. Wind turbine fault detection through principal component analysis and statistical hypothesis testing. Energies 2016, 9, 3. [CrossRef]

12. Hosseinzadeh, M.; Rajaei Salmasi, F. Analysis and detection of a wind system failure in a micro-grid. J. Renew. Sustain. Energy 2016, 8, 043302.

13. Zaher, A.S.A.E.; McArthur, S.D.J.; Infield, D.G.; Patel, Y. Online wind turbine fault detection through automated SCADA data analysis. Wind Energy 2009, 12, 574-593. [CrossRef]

14. Gibert, K.; Marti-Puig, P.; Cusidó, J.; Solé-Casals, J. Identifying health status of wind turbines by using self organizing maps and interpretation-oriented post-processing tools. Energies 2018, 11, 723.

15. Beretta, M.; Julian, A.; Sepulveda, J.; Cusidó, J.; Porro, O. An Ensemble Learning Solution for Predictive Maintenance of Wind Turbines Main Bearing. Sensors 2021, 21, 1512. [CrossRef] [PubMed]

16. Odgaard, P.F.; Stoustrup, J. A benchmark evaluation of fault tolerant wind turbine control concepts. IEEE Trans. Control Syst. Technol. 2014, 23, 1221-1228.

17. Vidal, Y.; Rodellar, J.; Acho, L.; Tutivén, C. Active Fault Tolerant Control for Pitch Actuators Failures Tested in a Hardware-in-theLoop Simulation for Wind Turbine Controllers. In Proceedings of the 23rd Mediterranean Conference on Control and Automation (MED), Torremolinos, Spain, 16-19 June 2015.

18. Badihi, H.; Zhang, Y.; Hong, H. Wind turbine fault diagnosis and fault-tolerant torque load control against actuator faults. IEEE Trans. Control Syst. Technol. 2014, 23, 1351-1372. [CrossRef]

19. Casau, P.; Rosa, P.; Tabatabaeipour, S.M.; Silvestre, C. Fault detection and isolation and fault tolerant control of wind turbines using set-valued observers. IFAC Proc. Vol. 2012, 45, 120-125. [CrossRef]

20. Kim, J.; Yang, I.; Lee, D. Control allocation based compensation for faulty blade actuator of wind turbine. IFAC Proc. Vol. 2012, 45, 355-360. [CrossRef]

21. Rotondo, D.; Nejjari, F.; Puig, V.; Blesa, J. Fault tolerant control of the wind turbine benchmark using virtual sensors/actuators. IFAC Proc. Vol. 2012, 45, 114-119. [CrossRef]

22. Sami, M.; Patton, R.J. Global wind turbine FTC via TS fuzzy modelling and control. IFAC Proc. Vol. 2012, 45, 325-330. [CrossRef]

23. Simani, S.; Castaldi, P. Active actuator fault-tolerant control of a wind turbine benchmark model. Int. J. Robust Nonlinear Control 2014, 24, 1283-1303. [CrossRef]

24. Yang, X.; Maciejowski, J.M. Fault-tolerant model predictive control of a wind turbine benchmark. IFAC Proc. Vol. 2012, 45, 337-342. [CrossRef]

25. Garelli, F.; Camocardi, P.; Mantz, R.J. Variable structure strategy to avoid amplitude and rate saturation in pitch control of a wind turbine. Int. J. Hydrog. Energy 2010, 35, 5869-5875. [CrossRef]

26. Ye, D.; Yang, G.H. Adaptive fault-tolerant tracking control against actuator faults with application to flight control. IEEE Trans. Control Syst. Technol. 2006, 14, 1088-1096. [CrossRef]

27. Li, J.; Wang, S. Dual multivariable model-free adaptive individual pitch control for load reduction in wind turbines with actuator faults. Renew. Energy 2021, 174, 293-304. [CrossRef]

28. Hur, S.H.; Reddy, Y.S. Neural Network-Based Cost-Effective Estimation of Useful Variables to Improve Wind Turbine Control. Appl. Sci. 2021, 11, 5661. [CrossRef]

29. Ma, K.; Soltani, M.; Hajizadeh, A.; Zhu, J.; Chen, Z. Wind Farm Power Optimization and Fault Ride-Through under Inter-Turn Short-Circuit Fault. Energies 2021, 14, 3072. [CrossRef]

30. Jonkman, J.; Butterfield, S.; Musial, W.; Scott, G. Definition of a 5-MW Reference Wind Turbine for Offshore System Development; NREL: Golden, CO, USA, 2009. 
31. National Renewable Energy Laboratory. OpenFAST Documentation; National Renewable Energy Laboratory: Golden, CO, USA, 2021.

32. Technology. FAST Tool Master 2021. Available online: https://github.com/TUDelft-DataDrivenControl (accessed on 12 August 2021).

33. Tutivén, C.; Vidal, Y.; Acho, L.; Rodellar, J. Hysteresis-based design of dynamic reference trajectories to avoid saturation in controlled wind turbines. Asian J. Control 2017, 19, 438-449. [CrossRef]

34. Wright, A.D. Advanced Control Design for Wind Turbines; National Renewable Energy Laboratory: Golden, CO, USA, 2008.

35. Hansen, M.H.; Hansen, A.D.; Larsen, T.J.; Øye, S.; Sørensen, P.; Fuglsang, P. Control Design for a Pitch-Regulated, Variable Speed Wind Turbine; Risø National Laboratory: Roskilde, Denmark, 2005.

36. Dykes, K.L.; Rinker, J. Windpact Reference Wind Turbines; National Research Energy Laboratory: Golden, CO, USA, 2018.

37. Friedman, J.H. Greedy function approximation: A gradient boosting machine. Ann. Stat. 2001, 29, 1189-1232. [CrossRef]

38. Pedregosa, F.; Varoquaux, G.; Gramfort, A.; Michel, V.; Thirion, B.; Grisel, O.; Blondel, M.; Prettenhofer, P.; Weiss, R.; Dubourg, V.; et al. Scikit-learn: Machine learning in Python. J. Mach. Learn. Res. 2011, 12, 2825-2830.

39. Liu, F.T.; Ting, K.M.; Zhou, Z.H. Isolation Forest. In Proceedings of the Eighth IEEE International Conference on Data Mining, Pisa, Italy, 15-19 December 2008.

40. Samani, A.E.; De Kooning, J.D.; Kayedpour, N.; Singh, N.; Vandevelde, L. The Impact of Pitch-To-Stall and Pitch-To-Feather Control on the Structural Loads and the Pitch Mechanism of a Wind Turbine. Energies 2020, 13, 4503. [CrossRef]

41. Ali, O.A.M.; Ali, A.Y.; Sumait, B.S. Comparison between the effects of different types of membership functions on fuzzy logic controller performance. Int. J. 2015, 76, 76-83. 